\title{
O DESDOBRAMENTO DA CIDADE/PAÍS NAS TRAMAS DO "ARBUSTO ESPINHOSO” DE LUÍS DILL
}

\section{THE UNFOLDING OF THE CITY/COUNTRY IN LUÍS DILL'S “THORNY SHRUB” PLOTS}

\author{
Christini Roman de Lima ${ }^{1}$
}

\begin{abstract}
"Escrever o que nesta terra de merda? Tudo que eu começo a escrever me parece um erro, como se estivesse fugindo do assunto. Que assunto? Merda! E quem disse que isso é responsabilidade minha? (A festa, Ivan Ângelo)
\end{abstract}

\begin{abstract}
RESUMO: Luís Dill apresenta em seu novo romance, Timbirupá, a história de uma cidade decadente (e fictícia) rumo à devastação. A narrativa fragmenta-se em diversas histórias pessoais paralelas e não lineares que intercalam tempos e espaços geográficos distintos em uma intrincada configuração narrativa; elementos que convergem no reflexo de um país sempre em processo, mas que não chega a se consolidar em tempo algum.
\end{abstract}

PALAVRAS-CHAVE: cidade; país; devastação; fragmentação.

ABSTRACT: Luís Dill introduces in his new novel, Timbirupá, the story of a decadent (and fictional) city heading for devastation. The narrative is fragmented into several parallel and non-linear personal stories that intersperse distinct geographic times and spaces in an intricate narrative configuration; elements that converge in the reflection of a country that is always in process, but that never consolidates itself.

KEYWORDS: city; country; devastation; fragmentation.

DILL, Luís. Timbirupá. Porto Alegre: Casa 29, 2020. 229 pgs.

O romance Timbirupá (2020) é a sexagésima obra publicada pelo escritor e jornalista Luís Dill. Ele estreou na literatura com A caravana dos diamantes, no ano de 1990, recebendo vários prêmios desde então. Dentre esses, o Açorianos, de Porto Alegre, na categoria Conto, com Tocata e fuga (Bertrand Brasil), de 2007; e na categoria Juvenil, com De carona, com nitro (Artes e Ofícios), de 2009, e Decifrando Ângelo (Scipione), de 2014. Além disso, foi finalista em sete indicações ao prêmio Jabuti. Em seu novo romance, Timbirupá, Dill apresenta a história da cidade fictícia de mesmo nome, uma cidade decadente que marcha rumo à devastação.

A intriga se passa entre os dias 13 e 14 de outubro de 1930 e tem como pano de fundo a Revolução ocorrida naquele ano. A narrativa centra-se em Timbirupá e nas 24 horas que envolvem a catástrofe. Ao foco central, entretanto, sobrepõem-se outras histórias, entrelaçadas nas intermitências dos 47 capítulos do romance. Essas narrativas, não lineares, intercalam

\footnotetext{
1 Universidade Federal do Rio Grande do Sul - UFGRS, Porto Alegre, Rio Grande do Sul, Brasil; https://orcid.org/0000-0001-6181-193X; christiniroman@gmail.com. 
tempos e espaços geográficos distintos, uma gama de histórias pessoais (que não são aprofundadas) e um intrincado e instigante jogo narrativo.

Para mais, Timbirupá conjuga em suas referências direta e indireta (alegórica), vários Brasis: o dos primórdios da colonização, o da Revolução de 1930, e o atual - representado de forma indireta. $\mathrm{O}$ Brasil do porvir também pode ser antevisto na obra como o espaço que avança em direção à ruína. Passado, presente e futuro, assim, convergem em um mesmo quadro: do país sempre em processo, sem chegar a se consolidar em tempo algum.

$\mathrm{O}$ enredo centra-se em marasmo, fofocas e elementos fantásticos, os quais convivem com a perspectiva de uma revolução distante de seus horizontes de preocupação - mas que, indiretamente, acaba por devastar o povoado. A história da formação de Timbirupá, personagem basilar do romance, é exposta à parte do enredo central.

O narrador destaca que o território em que a cidade foi edificada era composto por vegetação cerrada e rodeado por montanhas pedregosas. Seus primeiros habitantes pertenciam à tribo Yatukuwés. A procura por terras propícias para cultivo ou para criação de gado levou o homem branco - tropeiros a mando de fazendeiros - a adentrar a localidade em 1856. A tribo foi dizimada pela gripe em menos de um ano da chegada do branco. A perpetuação (ínfima) do sangue dos nativos deveu-se à violência dos estupros de suas mulheres.

A região era envolta por um arbusto espinhoso chamado pelos nativos de timbirupá, o que determinou a escolha do primeiro nome da localidade, Caminho dos Timbirupás. A denominação significava, na língua tribal, " "punho cerrado do mau' ou 'punho fechado do diabo"". O arraial Caminho dos Timbirupás nasceu, assim, no "centro da panela formada pelas colinas pedregosas" (p. 69). A posse das terras, nunca comprovada, foi passada ao jovem Adelino Brum em 1857. O povoado, em 1890, alcançou patamar de Distrito de Timbirupá. Tornou-se município em 1901, chamando-se apenas Timbirupá. Chegou a ter quatro engenhos e 110 casas em seu apogeu - logo após a emancipação.

No presente do enunciado, Timbirupá pautava sua economia na monocultura da canade-açúcar (agonizante) e tinha apenas um engenho. A cidade mantinha-se geográfica e culturalmente fechada em si mesma, economicamente atrasada e distante de qualquer progresso: sem luz elétrica, telefone ou pavimentação nas ruas, envolta em promessas / expectativas de progresso que jamais se cumpririam: "Ali, em Timbirupá, houvera uma cidade; agora apenas ares fantasmais. Timbirupá se esvaziara a ponto de ter mais casas do que gente para ocupá-las" (p. 33).

A localidade, sendo assim, nunca deixou de ser um povoado, uma aldeia. Sua extensão circunscrevia a praça (além dela, apenas o engenho). A rua que a contornava - eixo da localidade - recebeu o nome de seu patriarca (tempo depois de sua morte). Timbirupá, nesse sentido, orbitava continuamente Adelino Brum - não apenas ele, como também a violência base de sua fundação. Os habitantes, integrantes desse arbusto espinhoso, têm suas trajetórias, nesse sentido, cercadas por tragédias, torpezas ou perversidades. Suas histórias pessoais, assim como a da formação da cidade, ligam-se ao enredo central do livro, mas de forma paralela e fragmentada.

O romance, ademais, apresenta uma espécie de segmentação do narrador, em outras palavras, há uma tentativa de explicitar a participação das narrativas incorporadas à obra rematada. O discurso, desse modo, se articula sob diferentes prismas. Em uma face, tem-se o narrador que organiza e seleciona textos e documentos primários - como o relato de viagem de 1851, realizado pelo explorador suíço Matteo Huber - integrados na composição. Nas outras faces, distingue-se a letra dos sujeitos criadores das escrituras preexistentes, ou seja, das narrações que entram na obra de modo literal, dispostas pelo narrador/organizador de forma direta.

$\mathrm{Na}$ trama conjugam-se boatos, informação jornalística, editorial de opinião, relato de viagem do século XIX, texto enciclopédico com aspectos gerais da cidade, romance distópico. 
Tais modos de expressão, no entanto, apresentam fatos coincidentes com versões, na maior parte das vezes, dispares - gerando a reflexão em torno do que determina a credibilidade ou a legitimidade de um relato em detrimento de outro. A mistura de elementos discursivos dispostos no entrecho do romance pode ser vista, igualmente, como uma problematização do "contar", ou seja, da gradação em torno da enunciação tanto no que concerne a realidade cotidiana (expressa no enredo), quanto no âmbito da construção de uma "verdade" histórica (expressa pela forma).

Timbirupá orquestra, à vista disso, diferentes tipos de discursos em sua estruturação. Os múltiplos registros percebidos no romance levam a crer que três "penas" inscrevem suas linhas: a de Aristeu - disposta nas muitas laudas do projeto inconcluso dos "Aspectos Gerais de Timbirupá"; a de Lamartine, com a reconfiguração das folhas encontradas nas gavetas do colega, após sua morte (obra que Lamartine nunca chegou a finalizar); e a do narrador que reorganiza as demais histórias e tece comentários irônicos em relação à cidade e aos habitantes - não perdoando nem mesmo suas fontes: Aristeu Pena é o jornalista sensacionalista que "farejava sangue" (p. 18) e Lamartine Espósito é o "jornalista embusteiro" (p. 89) que trai a causa operária, o Partido e, para mais, forja uma trajetória pessoal de proezas.

A divergência dos registros, a título de exemplo, pode ser percebida pela forma enciclopédica de certos capítulos - algum desses contando com ilustrações. O narrador, ao final do romance, destaca que Lamartine guardou as laudas do colega falecido e suas ilustrações, dedicando-se a contar a história do município. A informação corrobora a hipótese de que esses capítulos possam ser a reprodução de parte dos "Aspectos Gerais": "O coiteté pertence à família dos Salaminus. [...] Na língua dos Yatukuwés, coiteté significa peixe do fundo que anda. Conforme relatos do viajante suíço Matteo Huber, o primeiro homem branco a estudar a tribo, a explicação do nome se deve à tradicional brincadeira dos indiozinhos" (p. 95).

A modulação utilizada nesses segmentos, entretanto, difere-se do capítulo 27 (que, por sua vez, também destoa dos demais). Tal fato pressupõe uma transcrição adicional; nesse caso, do relato do viajante suíço Matteo Huber. O relato do explorador suíço faria parte do material de pesquisa reunido por Aristeu: "Havia algum tempo reunia material de pesquisa, relatos, desenhos de próprio punho, e até exercícios de ficção, obrados com o intuito de preencher as lacunas não alcançadas por seu trabalho" (p. 65, 66).

O capítulo discorre sobre temática congênere àqueles atribuídos ao jornalista, porém com tom distinto - o que pode ser visto através do juízo de valor expresso em relação à tribo observada: "Como tantos outros selvagens, os Yatukuwés são propensos a danças. (...) $\mathrm{O}$ cancioneiro pagão não se pode entender, visto não possuir ainda adequado silabário. (...) Dependendo da ocasião, passam a noite em verdadeiro pandemônio" (p. 128).

De outra parte, a participação de Lamartine Espósito na obra final é controversa: ele pode realmente ter reelaborado o texto contido nas laudas encontradas, como aponta o narrador, mas pode ser outro embuste do "velho jornalista": "Foi fiel tanto quanto pôde, mas, como ele mesmo defendia, a ficção sempre preenchia as lacunas. Lamartine Espósito nunca concluiu o livro e muito do que redigiu entrou para o território das lendas" (p. 224).

A suspeita surge em função da caracterização feita pelo narrador - que pinta a personagem como um farsante. Lamartine, todavia, já interferira nas matérias jornalísticas de Aristeu Pena quando era seu chefe na redação da Gazeta. Lamartine Espósito, além disso, possuía autoridade para decretar se as produções encontradas tinham valor ou legitimidade, assim como para descartá-las - o que faz arbitrariamente com o romance escrito pelo colega, intitulado 1999, do mesmo modo com que se apropria das suas laudas consideradas relevantes.

O narrador destaca que o "velho jornalista" encontrou o original do romance de Aristeu, "seguiu achando-o sem propósito e jogou o calhamaço fora" (p. 223). Lamartine já censurara 1999 quando o subordinado lhe mostrou alguns trechos: "Achava inútil a história ser ambientada no futuro. É preciso falar do presente, rapaz. (...) Adiantou que o partido nunca 
aprovaria a publicação de texto tão pueril" (p. 66). O narrador afirma que Lamartine descartara os originais, mas ele apresenta um resumo no capítulo 12 - o que também gera suspeição em torno do narrador final e de seu discurso (se o outro descartou, como ele teve acesso ao trecho reproduzido?).

O "futuro folhetim" (p. 63) de Aristeu Pena, 1999, consistia em uma distopia. É versão entretempos de 1984, de George Orwell: escrita pelo primeiro no ano de 1930; publicado, na realidade concreta, pelo escritor britânico em 1949; e, como metanarrativa, reflete alegoricamente o "Novo Brasil" - o que, por sua vez, aponta para o título de Aldous Huxley, Admirável Mundo Novo, de 1932 -, um "país do futuro" decadente e a um passo da ruína [imagem que se forma a partir do desdobramento das facetas e realidades de Timburupá - porém, contrária ao vaticínio expresso no folhetim: de um Novo Brasil como "a pátria no comando de todas as outras" (p. 64)].

Cabe salientar, além disso, a oposição entre os dois jornalistas, Lamartine e Aristeu Pena, como problematização em torno do engajamento social e político não apenas das personagens, mas dos modos de escrita: postulando-se uma crítica social não restrita às formulações tradicionais, ao retrato realista e ambientado no presente - reivindicação ratificada através da permanência da obra de Orwell como denúncia aos regimes totalitários e ditatoriais.

A sobreposição dos contextos no romance (ou ainda, dos tempos histórico e narrativo) remeteria, assim, a um futuro de catástrofe desenhado no presente e reelaborando a partir do passado: da formação de um espaço erigido em violência e exclusão ou em inverdades e fraudes, bases essas reatualizadas circularmente, tal qual o conservadorismo, a opressão, a censura e o controle. Nessa perspectiva, ao passado dos exploradores, dizimando a tribo local, segue-se a Revolução em curso, de 1930, que dá início ao período ditatorial de Vargas, ao qual se enseja outra ditadura, a militar - período que, mesmo não sendo exposto no romance, pode ser entrevisto nos reflexos (ou nos traços de filiação) a que Timbirupá remete: Incidente em Antares (de 1971), de Erico Veríssimo, ou A festa (de 1976), de Ivan Ângelo², por exemplo.

Os elementos contextualizados (ou não) nos espaços-tempos do romance se estendem ao presente, à contemporaneidade do autor com o "nome na capa", dando a ver obliquamente nova emergência do conservadorismo, da repressão e da subordinação dos sujeitos engolfados em um outro "arbusto espinhoso", esse, agora, verde amarelo, que inversamente, no sentido do "duplipensamento" (Orwell, 2010), reivindica liberdades e transparências, mergulhado, no entanto, em fraudes, negação e no falseamento da história que se faz verdade. Assim, 1999 como desdobramento de 1984 (expoentes de um século pretérito ao contexto de publicação de Timbirupá) que, sobrepostos ao desfecho do romance, dão a ver o "mito" da cidade como metonímia do país do futuro culminando em ruínas. De resto, no entrelaçamento das tramas, da narrativa e das histórias pessoais paralelas (mas que se unem ao compor a cidade), prefigura-se um Brasil que orbita em violência desde sua colonização.

\section{REFERÊNCIAS:}

DILL, Luís. Timbirupá. Porto Alegre: Casa 29, 2020. 229 pgs.

ORWELL, George. 1984. São Paulo: Companhia das Letras, 2010.

\footnotetext{
${ }^{2}$ As filiações podem ser pensadas tanto em termos de temática, quanto de estrutura formal. O vulto de Incidente em Antares - ao qual se pode incluir o esboço do romance pensado por Erico, A Hora do Sétimo Anjo (alusão ao fim dos tempos do Apocalipse de São João), romance que resultou em Antares - parece um pouco mais nítido que A festa. A inspiração nesse último pode ser mais difusa porque seus veios vislumbram-se nos entrechos formais e narrativos de Timbirupá - mesmo que a fragmentação no romance de Dill não seja tão radical quanto a de Ivan Ângelo.
}

Rev. Bras. Lit. Comp. Niterói, v. 22, n. 41, pp. 140-144, set. /dez. 2020 
Christini Roman de Lima é formada em Comunicação Social (Jornalismo) pela Universidade de Passo Fundo (UPF). Especialista, Mestre e Doutora em Literatura pela Universidade Federal do Rio Grande do Sul (UFRGS), desenvolve pesquisas nas áreas de Literatura Brasileira e Portuguesa, atuando em torno das temáticas do feminino, da guerra, do trauma e da violência (entre outros).

Submetido em $15 / 06 / 2020$

Aprovado em 15/07/2020 